\title{
Remapping the Visual Contours: An Enquiry into the Film Narratives of Adoor Gopalakrishnan
}

\author{
Simi Varghese \\ Associate Professor, Department of Journalism, Prajyoti Niketan College, Thrissur, Kerala, India \\ E-Mail: nevkuto6@gmail.com
}

\begin{abstract}
Adoor Gopalakrishan has been the greatest film director who had elevated Malayalam film to the level of World Cinema. Truly, he is the master craftsman of Indian cinema second only to Satyajit Ray. He had discovered the identity of Malayalam through his visual narratives. He had metamorphosed each film as an experience and eked out a new visual repertoire for Malayalam films. Hitherto, no serious study has been conducted to absorb the visual magnificence of Adoor films. Concerted efforts have been initiated in other Indian languages and world languages to trace the visual dynamics employed in Adoor films. When foreign film critics approach his films seriously, even today we often falter to imbibe the film sensitivity and culture kickstarted by $\mathrm{Mr}$ Adoor Gopalakrishnan. Still, he is the 'unravished fragrance' of Malayalam film industry. Adoor has been truly one of the masters of world cinema and had carved a special niche for him in the global film map. My paper tries to portray the new visual fervor inculcated by Adoor films in the Malayalam psyche and will unravel the subtle nuances which deeply touch the labyrinthine milieu of Malayalam film world.
\end{abstract}

Keywords: Visual Repertoire, Labyrinthine Milieu, Metamorphosis.

\section{INTRODUCTION}

The Malayalam film history can be divided as before and after 'Swayamvaram'. It had gone to hibernation during the silent era (1928-31) and the long sixty years which followed. Nobody could realistically imbibe the spirit of Malayalam films and was existing in a dormant stage. Films had reached India within months after its invention. When world cinema embarked on an entourage to experiment with the visual smorgasbord extended by films, Indian filmdom appeased their hunger by traditional devotional films and a few socially orchestrated movies. During the fifties, the true Indian cinema was released in Bengali by Satyajit Ray. Close on the heels of Ray films, Ritwik Ghatak and Mrinal Sen had discovered the new prospects of films. In 1989, 'Bhuvan Shome' by Mrinal Sen inaugurated the New Wave Film Movement in India. The impact of 'screen' has been an evergreen phenomenon of Malayalam films. At a time when musical dramas have been ruling the roost, the growth of malayalam films was an offshoot of the new visual sensibilities. Initially, actors and actresses were enacting their roles by singing songs. Film world banked on actors and actresses with singing prowess. The films had grown through dialogues and the visuals enhanced its appeal. No screen play writer or director has been fully aware of the semantics and visual grammar of the silver screen. They had simply transformed the 'space' of the screen into various frames. The ambience has been artificially created in the studio. The concept of screen play has also been unheard of in the film world. Earlier, screen play writers were known simply as 'creators of dialogues'. The scripts of drama were much alike the screen plays of films. The live enactment on stage has been named as drama and when it is shot by a movie camera and exhibited in the theatre, it becomes a film. An experimental film which appeared at that time was 'Newspaper Boy' (1995). The first malayalam film which had shown the repercussions of 'Italian Neo-Realism'. It is doubtful that the open manifestations of Italian Neo-Realism like 'Rome Open City' or 'Bicycle Thieves' have been seen by the people who were behind the curtain of 'Newspaper Boy'. 'Pather Panchali' of Satyajit Ray has also not been released at that period of time.

Malayalam filmdom witnessed new sensibilities and vibrations in the beginning of the seventies. Film language has been experimented first in 'Olavum Theeravum' which appeared in 1970. The film invented that a movie should communicate through visual modules or frames. The screen plays of Mr M T Vasudevan Nair had focused more on visual narratives unlike the early screen plays. 'Olavum Theeravum' has been a relief as Mr P N Menon is known for his media awareness. But the melodramatic exposition of the story and the mediocrity of the acting sequences have negatively influenced the 'visual culture'. 'Swayamvaram' (1972) has been the first malayalam movie which had communicated through its visual language. 'Swayamvaram' has also been acclaimed as the first screen play with structural excellence. (Madhu Eravankara) The years spent in Pune Film Institute and the visual cultures imbibed by watching world classics have equipped Adoor to imbibe the new visual culture. Swayamvaram had given the clarion call that a film should communicate through visual frames and not through dialogues alone. During the mid-sixties, Adoor Gopalakrishnan had formed the 'Chitralekha' Film Society which provided film buffs a new opportunity to view world classics. The visual phantasmagoria unraveled by world classics helped the malayalee film directors to comprehend the plight of malayalam films. Film Society Movement had given birth to a new genre of film aficianados with new film sensibilities. Many young film directors were ready to venture out and follow the challenging track initiated by Adoor Gopalakrishnan. The films of the seventies employed the true language of the 
films. Technologically too, good films have appeared on the scene. Commercial films too have started communicating through the film medium. The scene got animated with the advent of screen play writers who were adept in the 'tricks of the trade'.

\section{FORM, STRUCTURE AND MODEL}

Though his film sojourn extended through more than 35 years, only 10 films have come up as Adoor films. These films stand a class apart in terms of theme and narration. A transparent thread binds them together. This is the hallmark of Adoor films. The structure and narrative techniques differ in each film. 'Kodiyettam' is considered as having the simplest narrative style. The protagonist Sankarankutty is a rustic villager. Lucid narrative style and simple rustic dialogues mark 'Kodiyettam' as a film with a difference. The whole story gets unraveled in the plot of a temple festival. The whole edifice of the film revolves round the preparation for the festival, the ecstatic levels of celebration and the culmination. The film opens with the bursting of 'Kathina' and ends with the same fire crackers. His film 'Naalu Pennungal' too reverberates with simple story telling techniques. Adoor has etched out the essence of Thakazhi's stories and had given a different visual treatment. It is also an eye-opener towards the plight of women. Stories of Thakazhi are noted for their simple narration. The film director too has tried to maintain the simplicity during adaptation. The director has done justice to the soul of the stories and communicated exceptionally well through the various visual modules. In 'Vidheyan' and 'Kathapurushan' too Adoor had followed a simplistic structure which unfolds the story in a poignant manner. The tragedies of the protagonist get a magnificent visual interpretation in the hands of Adoor Gopalakrishnan. In 'Kathapurushaan', time is a major factor. The life of Kunjunny from his birth to the time he becomes a middle-aged man has been interpreted in the backdrop of the political and social milieu of Kerala. As the story unfolds, Adoor has employed a unique narrative technique which renders a whiff of fresh air to the otherwise mediocre story.

The varied visual dimensions have been experimented in the narration of 'Swayamvaram'. The bus journey in the beginning is also a rarity in malayalam films. Hitherto, we have not seen such a long journey in movies. This has eked out great controversy at that period of time. This has indirectly been a method employed by the director to portray the life journey of a human being. Background sound mixing had changed the narrative dynamics of the film. This is visible when the film concludes and the complexities of narration get manifested. Structurally, 'Mukhamukham' and 'Anantharam' are two films which appear a bit complicated. In 'Mukhamukam', different dimensions have been juxtaposed in a labyrinthine milieu. The return of Sreedharan in 'Mukhamukham' might be a reality or a dream by the people. Truth and myth have been interspersed in the visual narrative technique. Flashback has not been employed in the film. The memories of people regarding Sreedharan had been sandwiched one after the other. The memories begin with the owner of the tea shop who is not very close to Sreedharan and ends with his own son. It exhibits the behaviour of a uni-focussed circle. The journey can be imagined as from the superficial to the subtle, the change from a materialistic journey to a spiritual journey. The visual frames before and after Sreedharan's come back have a uniqueness attached to it. This has been employed in the imagery of a mother and child. The child sleeps while its mother is asleep and at the same time is awake. The mother hears about Sreedharan's murder. But the audience can have a different interpretation; it can be real or else a dream.

The structure of 'Anantharam' traverses through the pattern of monologue. Time appears before us as a fleeting sensation. The past and the future remain entangled in a complicated situation. The protagonist Ajayan narrates the story. But it is a totally different story. In one story he presents himself as a super human with rare prowess. The society is unable to contain his acumen and abilities. Society tries to traumatize him in many ways. The second story narrated by Ajayan is about his traumatic childhood and the fearful incidents. He gets trammeled up in a world mired by truth and fiction. Such series of incidents have complicated his social sphere. Moreover, the elderly servants at home have created a barrier triggered by lies and fantasies. Finally, Ajayan reaches a mental status where he is unable to figure out reality and myth. Love for Ajayan is something disturbing. His heart yearns for true love. He sees his brother's wife as Nalini which is a turning point of the film. The comment of Adoor regarding 'Anantharam' is noteworthy. 'The reality outside the frame is always trying to correct the reality within the frame'. The reality portrayed in the visual frame of 'Anantharam' becomes unrealistic many a time in 'Anantharam'. A driver is visible in the front seat. The audience heaves a sigh of relief as the car which has been in the car porch gets moved. At that point of time different things crowd up into the frame and the existing things in the frame get sidelined and insignificant. The dimensions of our sight get a shock when we see a tractor pulling the car. The scene changes in a split second and the audience remains confused and dumbfounded. Another context portrays Balan as a boy sleeping in a dark room. From the darkness, three impish characters emerge. They intimidate Ajayan. But when he opens the windows, light enters the room. The time has changed to noon. Those impish characters were his own elderly servants. The appearance of light had totally changed the concept of reality. Our dimensions of reality undergo a sea change in the film.

The story within the story is the attraction of 'Nizhalkuthu'. The hangman Kaliyappan has reached the jail for executing the hanging. The night before the execution, the wardens of the jail narrate a story to him. He takes the story as his own. His daughter Mallika and his son-in-law Vasu remain as the story within the story and destroy the life of Kaliyappan. When his own fears appear as fantasies, the film gains a rare visual dimension. An old man appears both in the beginning 
and end of 'Kathapurushan'. He narrates a story which had taken place in the forest. The story of a prince and a giant. One part of the story unravels in the beginning and the end of the story appears at the end of the film. Meanwhile, the story of 'Kathapurushan' unfurls. The story teller, the episodes in the story, the person who ends the story - this structure of the film makes it beautiful and thought provoking. Adoor Gopalakrishnan belongs to a rare genre of film directors who gives much importance to the form and structure of a movie. The frames of Adoor often manifest the aggressiveness of a mathematician. An unnecessary shot is a rarity in Adoor films. Adoor exhibits greatest dexterity in the selection of frames and in the aesthetic blending of light and shadow for placing the animate and inanimate objects. The greatest criticism leveled against Adoor films is that when he strives for excellence in craft, often the emotional fervor is the biggest casualty. Each visual frame is an index regarding the wholeness of the film. Each index reverberates with the visual dynamics of Adoor as a greatest artificer. Through certain indices, he imparts emotional flavor to the various layers of meaning.

In 'Anantharam', the boy counting odd and even numbers sitting at the stone steps of the pond is an index. Odd numbers are not complete in it. Likewise, even numbers alone are incomplete. No story is complete in itself. It is a continuum which never stops. This number matrix communicates about the plot of 'Anantharam' and the mental status of Ajayan. In 'Kathapurushan' too there is a similar comparable situation. Meenakshy and the young boy Kunjunny play by repeating the alphabet. The film ends in a laughing sequence where Meenakshy, Kunjunny and their son end their game of repeating letters. It is an unending scene of laughter.

'Mathilukal' is another visual feast offered by Adoor. It has been a greatest example set forth by Adoor focusing on the structure. He introduces the character Narayani as a voice from the other side of the wall. Many directors have ventured into produce Basheer's 'Mathilukal' as a film. Most of the screen play writers wanted to bring Narayani to the forefront. Basheer talks to Narayani who is on the other side of the wall. He talks to her with all the emotional vagaries of an alienated man. Narayani submits to him and gets unraveled before him in the splendor of a true woman in flesh and blood. The last hope that they can meet in the hospital also remains a distant unrealized wish of both of them. With never ending aspirations, the twig which scales up to the sky reserves a tinge of sorrow in the minds of the audience. This wonderful alchemy is revealed in Adoor's 'Mathilukal'.

\section{PERFECTION OF SCREEN PLAY}

Screen play is the reading format of a film. It aesthetically sketches the subtle moments in a paper. The presence of a screen play has been felt in the beginning in 'Swayamvaram'. Adoor himself had penned the scripts of all his films. The perfection of screen play is one of the hall marks of Adoor films. His well-nurtured screen plays enhance the beauty of his films. Adoor often focuses on the visual language when he manifests a character or a story situation into the paper. He included in his scripts the natural sounds and details of musical direction. Adoor has been a screen play writer who had perfectly comprehended the visual language of the films. When scenes form from shots and sequences form from scenes, they possess visual continuity and strength. His pre-planned and prepared screen plays don't bring about changes. Changes may happen with the possibilities of a location.

\section{UNDERSTANDING THE VISUAL LANGUAGE}

Every film has a language and a grammar which ensures the correct usage of language. An ambi-dexterous film maker only can produce films in a perfect way. Adoor has mastered the visual syntax and grammar after great training. This bears testimony of the fact that 'Swayamvaram' is the first realistic film in Malayalam. The perfect film language is an invention of Adoor Gopalakrishnan. Film is an audiovisual medium and a director studies all the nuances of film language and culture. Judicious use of visual and audio modules imparts meaning to a film. Factors like shots, angles, movement of camera and objects, selection of lens, usage of light, acceptance of various hues and colours etc control the visual language. Editing imparts meaning to the various shots. Adoor is a staunch disciplinarian in executing these facets of film technology. Adoor has been exalted as a master of world cinema by virtue of his meaningful shots in each film. Unni of 'Elipathayam', Sankarankutty of 'Kodiyettam', Basheer in 'Mathilukal' and Patelar in 'Vidheyan are pertinent examples of experimenting with film language.

\section{CLASSIC NATURE OF FILMS}

Classic films demand repeated viewing. Each sight triggers new dimensions for audience. Audience has been exalted to new aesthetic sensibilities. Classic films surpass time and space. Even today 'Wild Strawberries' of Ingmar Bergman, 'Pather Panchali' of Satyajit Ray, 'Gold Rush' of Charlie Chaplin, 'La Strada' of Federico Fellini and Rene's 'Hiroshima Mon Amar' elevate audience to ideal heights of visual excellence. Films ranging from 'Swayamvaram' to 'Naalu Pennungal' have carved its own niche in the cultural repertoire of Kerala.

\section{FILM AND AUDIENCE}

A good book stores some thought provoking ideas to the reader. Film too has some virtues in store for its audience. Commercial films never store anything for the audience. Audience experiences a kind of vacuum after watching such films. Such films which don't provide food for thought for the brain bring forth momentary pleasure for the audience. The lion's share of the films belongs to this genre. But the visual frames of Adoor's films make the aesthetic journey towards the audience easier. In the last visual sequence of 'Swayamvaram', the door remains closed before Sita. The 
cruel worldly voices reverberate outside. Sita is free to choose her world all on a sudden. Audience too can help out Sita in finding out her ideal world.

In 'Elipathayam', Unnikunju retreats to his own place owing to the selfishness of the world. As a revelation he understands his world. His life may further undergo unforeseen changes. In 'Kathapurushan' even at the end, the protagonist Kunjunni appears as a conundrum in the psyche of the audience. The theme, plot and characters of Adoor films haunt the audience always. Most of the characters of Adoor films carry the past with them. The only exception is Viswan and Sita of 'Swayamvaram'. Though Ajayan, his brother and his brother's wife live in the liquid present, the past haunts him always. In all films there is a divide between the film time and the story time. Feudal system has been on the decline and Unni of 'Elipathayam' is a representative of that turbulent period of time. He is the last person in the feudal family set up. The period mentioned in 'Mathilukal' represents the rule of the king. Costumes, ambience and dialogues have etched the essence of that period of time. 'Mukhamukham' represents a period of 'Communist International' and fiery speeches. Adoor often decides the period of his films through certain dialogues of his characters, their costumes and very subtle indicators.

\section{CONTEMPORARY RELEVANCE - PLOT}

All the plots in Adoor films are punctuated by contemporary relevance. Basheer in 'Mathilukal' vociferously yearns for freedom from the jail and when he gets freedom, questions its relevance. It's a threatening reality that in the postindependent society, man is moving towards 'freedomlessness'. The power struggles in 'Nizhalkuthu' entangle the ordinary citizen. The plight of the four women portrayed in 'Naalu Pennungal' is still worse. Even today the cries of slaves like Thommi and Omana fall on deaf ears. The practicality of modern world has changed many communists and they had crushed the hard exteriors of revolution and embraced fresher and more greener pastures in life.

\section{SERENITY AND RUSTICITY OF KERALA}

The nostalgic sensibilities mark the films of Adoor Gopalakrishnan. Though he traverses through the inner crevices of human life, the backdrop of his stories find its locale in the villages of Kerala. He tries to retain the 'little, nameless acts of kindness and love', in almost all his films. The backdrop of 'Kodiyettam' is the festival in their village. Here the rustic nature becomes the indispensable feature of the story. Dark mountain ranges, green paddy fields, wind which sways the coconut leaves etc are just like characters which complement the frames in 'Nizhalkuthu'. In 'Kathapurushan', nature evolves as a soothening agent. Almost all of Adoor's characters hail from villages. Adoor films are always punctuated with ponds, paddy fields, rain, stone steps, coconut fields, narrow roads etc. Adoor seeks that 'malayalee identity' in his films. The repercussions of tradition and culture help in the visual manifestation. Here films portray the celebration of humanity. The hangman of 'Nizhalkuthu' though has in him 'the milk of human kindness' in abundance cannot impart the love. ('Film World of Adoor' - Dr M D Manoj) Often he is forced to hang innocent people. Though he does the act, his mind is always with the convict. The unblemished humanity in Kaliyappan is well-celebrated by Adoor in 'Nizhalkuthu'. Basheer the writer is put in jail being accused as a traitor. He happily accepts the friend who is in chains and fetters in jail. The director pinpoints the profound love and simplicity of Basheer in 'Mathilukal'.

\section{CHARACTERS AND NARRATION}

Adoor had employed a narrative technique which goes deep down into the human psyche. He makes use of the audiovisual possibilities of the medium for that purpose. Certain metaphors, interventions and dialogues help the audience to undertake a journey to reach the character. At times the story situations explain the nature of the characters of the film. In commercial films we often watch films of male supremacy. When directors write for super stars, when they become spokesmen of power, they only portray stories of male chauvinism. Often women become satellite characters which often revolve around male characters. But those men exhibit the strength and weakness of any man next door. They stand on a par with them. Women are not embodiment of frailty in Adoor films. They are strong icons of enhancement of female strength. Sita in 'Swayamvaram' faces life with all its brutality after the death of Viswam. In 'Kodiyettam' the sister and wife of Sankarankutty are strong women. Irresponsible Sankarankutty reaches the higher echelons of life because of his sister and wife. In 'Elipathayam', the second sister Rajamma of Unni is an embodiment of great patience. His elder sister and younger sister Sreedevi often hate him. Unni is a simpleton before them. Savithri in 'Mukhamukham' never approves of all the gestures of Sreedharan. As the loveable sister-in-law, Suma becomes the soul mate of Ajayan in 'Anantharam'. In 'Mathilukal', Narayani is ready to accept all the roses in the world from Basheer. In 'Kathapurushan' even at a very old age, 'tharavattamma' reigns supreme in the family. In 'Nizhalkuthu', Kaliyappan is being treated as her son by his wife. The female characters Kunjupennu, Kumari, Chinnuamma and Kamakshi are equally strong and powerful. Adoor introduces women characters in all their power, splendor and glory. He proclaims that women are to be respected and they should be given a respectable position both in the society and in their families.

\section{AUTOBIOGRAPHICAL CHARACTERS}

The treasure of an artist is his experiences in life. It can be attained through his life or through the experiences of his friends. These experiences enter the foundry of time and become subtle and profound. Therefore autobiographical elements may crop up in his scripts. In many films, the characters closely resemble his own life and characteristic features. Manifestation of experiences determines the goodness of a film. In 'Kathapurushan' autobiographical 
elements are more. The life of Kunjunni has some resemblance with Adoor and the film shot in his own 'tharavadu' speaks volumes of his attachment to the character. The rustic backdrop and festivals have been recreated from his own village. This is true in the case of 'Elipathayam' also.

\section{RELEVANCE OF BACKGROUND MUSIC}

There is always an ideal relationship between music and film. The objective of music is to provide emotional intensity to the scenes and sequences. Sooner, songs entered the scene. With songs and the incessant background music, film has lost its individuality. In Indian films, song became an indispensable character. The best films in Indian films employed background score in an exceptional manner. Hariharan when he reaches from Benares enquires about Durga to his wife. She had died earlier. Surbajaya remains silent. The sobs of Thar-Shehnai in the backdrop reveal everything to Hariharan. Adoor too has employed background score in a very creative manner. Adoor had taken the service of the best musicians in South India. He had used music as a motif in his films. In 'Elipathayam' Adoor employs a music when Sreedevi carries the rat to the pond to kill it. Finally when Unni too is downed in the pond, the same music gets repeated. In'Kodiyettam' background music has not been used. 'Kodiyettam' in a way questions the necessity of using background music when the film had creatively used the natural sounds. The eloquence of silence and sight has been deep rooted in the consciousness of Adoor that he alone can think about the visual dimensions of background music.

The art life of Adoor Gopalakrishnan repletes with perfect accountability and genuineness. Adoor has not at all deterred from the path of veritable art. The spokesmen who appeared after Adoor as the protagonists of New Wave Cinema had either gone for fresher pastures or else stopped midway. The 'classic director' of Indian cinema had kindled a new sensibility for Indian films. The perfection seen in each of his films deserves special mention. A re-reading of the films of Adoor Gopalakrishnan energises our own sensitivities and artistic imagination. Truly, here lives a great man who had brought home the greatest film award 'Dada Saheb Phalke Award' for the first time.

\section{CONCLUSION}

Adoor films are noted for their special narrative techniques. These films have carved their special niche in the academic map of world classics. Truly, these films had initiated deeper evolutionary contours for the metaphorical structures of neo-realistic films. Adoor's own words bear testimony to his convictions. "I have been successful in portraying characters which honestly represented the social life in some way. My films represent very relevant social issues.” Renowned actor Madhu evaluates globally acclaimed director Adoor in these words, "When others produced films, Adoor created life itself.” His guru G Sankarapillai at Gandhi Gram Rural Institute, Mathura had influenced him in a great way. 'Pather Panchali' which he happened to see while he was studying there had enflamed his dreams to switch over to films. His stint at Pune Film Institute hobnobbing with great doyens Ritwik Ghatak and Satish Bahadur had endeared him more towards his bastion. Adoor has been fortunate to receive rave reviews for his films. British critic Sarah Madual writes about his 2002 film 'Naalu Pennungal': 'Though his films portray the stories before half a century, the women in his films reflect the stark realities faced by the modern women. In that case, the relevant 'Naalu Pennungal' is a mirror. The reflections on it make us disturbed.' Generally, Adoor films have stood the test of time and space. His films conversed with the 'man in the street'. All his films have marked the subtle nuances associated with his homeland Kerala. Nonetheless, his films had endeavoured to achieve a special genre of cultural accountability.

\section{REFERENCES}

[1] McQuail, Denis. (2010). Mass Communication Theory. New Delhi: Sage.

[2] Santhosh kumar, T K. (2014). Malayala Television Charithram. Kakkanad: Kerala Press Academy

[3] Jacob, Shaji. (2004). Television: Kazhchayum Samskaravum. Kozhikode: Haritham Books.

[4] Sivasankaran, M K. (2011). Prakshepana Kala Charithram. Thiruvananthapuram: Kerala Bhasha Institute.

[5] Athique, Adrian. (2012). Indian Media. UK: Polity Press.

[6] Ramachandran Nair, Panmana. Ed. (2016). Chalachithra Pattanangal. Kottayam: Current Books.

[7] Kupsc, Jarek. (2010). The History of Cinema for Beginners. New Delhi: Orient Blackswan.

[8] Thiruvoth, Anil Kumar. Ed. (2014). Masters of Indian Cinema. Kozhikode: Progress Publication. 